DOI: $10.25100 /$ pfilosofica.v0i50.8792

\title{
TIEMPO E HISTORIA: CONTRIBUCIÓN A UNA FILOSOFÍA SOCIAL CRÍTICA
}

\author{
Fernando Forero Pineda \\ Departamento de Filosofía, \\ Universidad Nacional de Colombia, Bogotá, Colombia.
}

\begin{abstract}
Resumen
Con recurso a las filosofias de Heidegger y Gadamer, a las que confrontamos con la teoría crítica, este artículo vuelve sobre el diálogo entre filosofía e historia. Cuando se leen estos dos autores en contraste con esa otra corriente de pensamiento, empiezan a hallarse resonancias e implicaciones mutuas, así como también las divergencias que se presentan. Desde esta confrontación pretendemos acceder a una consideración del tiempo y de la historia que permita elaborar desde alli una filosofía crítica. El artículo hace productiva para una filosofía social las ontologías de la historicidad y del tiempo de Gadamer y Heidegger.
\end{abstract}

Palabras clave: tiempo; historia; crítica; filosofía hermenéutica; teoría crítica.

Cómo citar este artículo: Forero-Pineda, F. (2020). Tiempo e historia: Contribución a una filosofía social crítica. Praxis Filosófica, (50), 121-140. doi : 10.25100/pfilosofica.v0i50.8792.

Recibido: 18 de septiembre de 2019. Aprobado: 31 de octubre de 2019. 


\title{
Time and History: Contribution to a Social Critical Philosophy
}

\author{
Fernando Forero Pineda
}

\begin{abstract}
Supported by the philosophies of Heidegger and Gadamer, whose we confront with the critical theory, this article returns to the dialogue between philosophy and history. When these two authors are read in contrast with that other stream of thought, resonances and mutual implications start to be found, as well as the divergences that present themselves. From this confrontation we intend to access to a consideration of the time and the history that allows to elaborate a critical philosophy. The article makes Gadamer's and Heidegger's ontologies of historicity and time productive for a social philosophy.
\end{abstract}

Keywords: Time; History; Critique; Hermeneutical Philosophy; Critical Theory.

${ }^{1}$ Doctor en filosofía de la Fern-Universität Hagen (Alemania) y de la Universidad Nacional de Colombia; realizó su doctorado en el marco de la Deutschlateinamerikanisches Forschungs- und Promotionsnetzwerk Philosophie. Es magister en filosofía de la Universidad Nacional de Colombia y licenciado en ciencias sociales y sociólogo. Hace parte Grupo de Investigación en Hermenéutica Contemporánea (Universidad Nacional de Colombia). En su investigación doctoral se ocupó de la evolución de la filosofía hegeliana en el periodo de Jena y particularmente del concepto de negatividad en aquel joven profesor. Sus campos de interés son las fuentes de la filosofía de Hegel (Platón, Aristóteles, Kant, el romanticismo y el idealismo poskantiano) y las prolongaciones de la filosofía hegeliana tanto en la vertiente de Marx y el marxismo como en la de la filosofía hermenéutica (particularmente en Heidegger y Gadamer). Otra de sus áreas de interés es la teoría social clásica y contemporánea. Ha realizado investigaciones sobre teoría social clásica (Marx, Durkheim y Weber), y sobre el pensamiento social y político en la Escuela de Frankfurt (Adorno, Horkheimer, Marcuse, Habermas, Honneth y los recientes trabajos de Hartmund Rosa, Reiner Forst y Rahel Jaeggi).

ORCID: 0000-0002-0664-5016 E-mail: jofforeropi@unal.edu.co 


\title{
TIEMPO E HISTORIA: CONTRIBUCIÓN A UNA FILOSOFÍA SOCIAL CRÍTICA
}

\author{
Fernando Forero Pineda \\ Departamento de Filosofía, Universidad Nacional de Colombia, Bogotá, \\ Colombia.
}

Este artículo se propone reunir a la filosofía hermenéutica con la teoría crítica y desde allí elaborar una filosofía crítica de la historia y del tiempo. La tarea no es evidente, pues hay una especie de repulsión entre ambas corrientes de pensamiento; los antecedentes de esta discusión datan de siglos atrás en el debate Hegel-Marx, pues la filosofía hermenéutica encuentra una de sus fuentes fundamentales en el idealismo alemán clásico, y particularmente en la filosofía de Hegel, mientras que la fuente principal de la teoría crítica es Marx. En su momento Marx señaló que en la dialéctica hegeliana no hay una transformación real del mundo, sino solo una solución armónica de las contradicciones que tiene lugar al nivel del concepto. Para Marx, la dialéctica es, en el fondo, pura abstracción; le hace falta una transformación concreta del mundo real y eso es lo que ofrece su pensamiento: una praxis revolucionaria que transforma las condiciones de vida de los individuos sometidos a la lógica del capitalismo. Hegel elabora una crítica de su mundo, pero cuestiona el pensamiento reducido a entendimiento; propone, por su parte, un saber absoluto en el que se reúnen las contradicciones, pero esa propuesta deja intocada la realidad. La crítica de Marx a Hegel es que su resolución de las contradicciones solo tiene lugar a nivel de la idea (Marx, 2013, p. 142). Hegel no pudo responder a Marx, pero sí lo hicieron algunos de sus discípulos, que consideraron muy pronto que a la praxis revolucionaria le hacía falta hondura filosófica y dialéctica, como la que 
solo Hegel y el hegelianismo estaban en condiciones de ofrecer (Rosenkranz, 1844, p. 405). Este debate se reproduce a principios del siglo XX cuando Adorno y Marcuse entraron en confrontación, esta vez con la filosofía de Heidegger (Marcuse, 1928, p. 364). Ser y tiempo y los escritos anteriores a esta obra fueron objeto de debate por parte de los teóricos críticos, no ya la obra posterior de Heidegger que se vuelve cada vez más ontología pura y que, además, constituía la expresión de un filósofo cuyos vínculos con el nacionalsocialismo eran incontestables.

Lo interesante de volver a este debate es que uno siente la misma tensión cuando se acerca a filosofías más contemporáneas, como las de Honneth y Taylor. Así, en los trabajos de los años noventa de Honneth se señala que la patología del mundo contemporáneo es la falta de reconocimiento, y se halla el gesto de la teoría crítica de construir una teoría sólida de lo que es el reconocimiento apoyada en el psicoanálisis, la lingüística, las ciencias cognitivas, etc., a la luz de la cual se puede detectar la ausencia de reconocimiento ${ }^{2}$. Esto contrasta con Taylor, quien se aproxima fenomenológicamente a la experiencia del reconocimiento: el reconocimiento no debe ser teorizado desde fuera, sino asumido como una experiencia, es el modo como el existir es lo que es, pero que se ha desviado en el mundo contemporáneo (Taylor, 2009, p. 104). La crítica que emerge del planteamiento de Taylor sobre el reconocimiento señala que en el mundo contemporáneo se cierra la apertura de sentido y se impone una sola visión de mundo (Taylor, 2005, p. 220). Honneth y Taylor buscan deformaciones del mundo moderno, pero mientras Honneth lo hace a la luz de una teoría universal, Taylor lo hace a la luz de una experiencia universal que es la de la permanente variabilidad y reconstitución del sentido.

Al verlo desde la distancia, el debate se muestra como uno de dos viejas casas o familias, que han peleado por generaciones. Se atraen porque encuentran elementos en común, pero al mismo tiempo se repelen. Se trata de tradiciones que, cuando dejan de mirar sus propios proyectos para ver lo que están haciendo sus contemporáneos, advierten que, si bien hay puntos en común, en últimas no tienen mucho que ver entre sí. ¿Qué hay de fondo en

${ }^{2}$ Honneth se apoyaba en el Hegel del periodo de Jena, pero esta filosofía le parecía demasiado especulativa de modo que acudía a los datos empíricos y a las teorías que solo la ciencia puede ofrecer (Honneth, 1998, p. 114). Pero en los años 2000 el mismo Honneth practica un giro decisivo: va a una ontología fenomenológica del reconocimiento y desde allí pretende desarrollar una teoría crítica de la sociedad. En este momento conecta con Heidegger desde donde vuelve a introducir el tema de la alienación que venía de Marx (Honneth, 2007, p. 37). Sobre el diálogo Marcuse-Heidegger (De Lara, 2014, pp. 23s), y sobre la confrontación Adorno-Heidegger (De Lara, 2019, pp. 7ss). Entorno al debate Hegel-Marx (Gama, 2018, pp. 29ss. y Forero, 2018, pp. 229ss.). 
todo esto? Bien vistos, los puntos de confrontación parecen mínimos y las convergencias, por ejemplo, en el diagnóstico del mundo contemporáneo, son bastante fuertes.

El distanciamiento radical entre los filósofos críticos y la filosofía hermenéutica se ha venido cerrando. En las últimas décadas se puede ver un intento del lado de la teoría crítica por acudir cada vez más a la filosofía hermenéutica y un intento de la filosofía hermenéutica por aclimatar su ontología en una filosofía social y política. Curiosamente, un concepto en el que se muestra esta convergencia es en el de alienación, que viene de los Manuscritos del 44 de Marx. Se trata de un término bastante complejo, sobre el cual autores recientes vuelven y al que ponen en consonancia con la filosofía hermenéutica y en particular con la filosofía de Heidegger (Jaeggi, 2014, p. 25). Extrañamiento es un término que Marx toma de Hegel; él elabora un enfoque sobre la alienación desde la crítica de los modos de producción capitalista que hacen del mundo algo ajeno: allí el trabajador no se identifica con el mundo de objetos que produce. Pues bien, este mismo concepto sirve para medir la convergencia de las dos corrientes de pensamiento. Los mismos Heidegger y Gadamer tienen indicaciones por las cuales se puede desarrollar una teoría de la alienación. En la filosofía social contemporánea se muestra, por ejemplo, que hemos perdido todo tipo de pertenencias: no nos reconocemos ni en nuestros vecinos o colegas de trabajo que dejan de ser individuos con los que se comparte el mundo y se convierten en rivales en la competencia (Rosa, 2016, p. 71). El término alienación señala así una suerte de pérdida de mundo, y es por ello que se puede poner en diálogo con la filosofía de Heidegger.

No obstante, en la breve descripción ya elaborada se ve que hay una suerte de desequilibrio entre ambas corrientes de pensamiento, pues la teoría crítica es de inmediato una filosofía social y se presenta de entrada con un programa político y de análisis social definido. La filosofía hermenéutica, por su parte, no ha desarrollado muchos planteamientos en esa dirección. Se plantea entonces el desafío de poner a hablar a Heidegger y a Gadamer sobre filosofía social, pues ello no es evidente y no es su propósito. En algún sentido, debemos seguir elaborando la obra de la filosofía hermenéutica, pues ni en Heidegger ni en Gadamer puede uno visitar un trabajo en el que elaboren sistemáticamente una filosofía social o política, como sí se lo encuentra en los teóricos críticos.

Como lo señaló Ricoeur, un pensador como Heidegger va a la profundidad del ser, pero se queda allí sin ser capaz de elaborar una suerte de "dialéctica descendente", es decir, sin volver a un ámbito de la experiencia como lo es la vida en comunidad o lo social (Ricoeur, 1986, p. 343). 
Su denuncia de que la metafísica achata la temporalidad al dimensionar únicamente la presencia, su indicación de que la experiencia humana es temporal en todas sus dimensiones, parece absolutamente acertada. Sin embargo, queda el sinsabor de que esto no sirve para mucho, de que se trata de un nivel demasiado básico que no cambia en nada el mundo real. Ricoeur reconoce que Gadamer sí tuvo el interés de volver a estas regiones: después de detectar la linguisticidad de la experiencia humana, al final de Verdad $y$ método, se esforzó por determinar cómo funciona esto en la historia, en la ética, en el arte, y en otras regiones de la experiencia. Más aún, a partir de los años ochenta él empieza a desarrollar planteamientos en la dirección de la filosofía social y política (Gadamer, 2000, p. 178).

Este artículo pone a hablar a Heidegger y a Gadamer con la teoría crítica, es decir, con aquella tradición de pensamiento que se vio a sí misma como rival de la fenomenología hermenéutica. Cuando se leen estos dos autores en contraste con esa corriente de pensamiento, se hallan resonancias e implicaciones mutuas, así como también divergencias profundas. Nos ocupamos del diálogo entre teoría crítica y filosofía hermenéutica, que queremos iluminar desde algunos planteamientos sobre la historia y el tiempo presentes en Heidegger y Gadamer. Ahora bien, no me interesa, como lo hizo Ricoeur en su momento, superponer una tradición en la otra: encontrar elementos críticos en las filosofías de Heidegger y Gadamer, y presupuestos fenomenológicos y hermenéuticos en la crítica de las ideologías (Ricoeur, 1986, pp. 351ss.). Más bien, el recurso a la crítica de las ideologías debe permitir el proceso de descenso hacia una filosofía social y política de los planteamientos de la fenomenología hermenéutica. No se trata de sostener que tenemos aquí dos filosofías complementarias, que una arranca donde empieza la otra, sino de indicar una filosofía que debe aclimatarse en el campo de lo social. La hermenéutica filosófica no sabe qué consecuencias se siguen de ella para una filosofía social y política; por eso, al identificar una filosofía crítica desde la fenomenología hermenéutica, lo que veremos es que la crítica que de allí resulta no es la misma que la crítica de la teoría crítica.

\section{Crítica de los teóricos críticos a las filosofías de Heidegger y Gadamer}

Para Heidegger y Gadamer la interpretación y la compresión son la forma de estar el ser humano en el mundo, de modo que se vuelven dimensiones inherentes al existir. Siempre estamos comprendiendo e interpretando, esto es, en presencia del sentido y en un entorno que nos es significativo. La existencia humana se mueve en esa dimensión de comprensión de sentido y de interpretación de su realidad y eso no es algo que podemos pasar por alto, sino que es su condición ineludible. Este planteamiento ya aparece 
en el Heidegger temprano e incluso en Ser y tiempo, que aún elabora una hermenéutica de la existencia humana. Esta obra se proponía plantear la pregunta por el sentido del ser, pero antes de eso Heidegger considera necesario hacer una hermenéutica del existir humano. Sabemos que después de Ser y tiempo Heidegger se vuelca por completo a la pregunta por el ser y esos análisis hermenéuticos quedan atrás. Pero todavía allí la hermenéutica sigue siendo ontológica, se centra en mostrar cuáles son esas formas fundamentales de la existencia humana, las estructuras generales del existir, la comprensión, la interpretación, el lenguaje, y la mayor parte del trabajo de Gadamer en Verdad y método es analizar la forma de realización de la comprensión y de la interpretación.

Ser y tiempo constituye una exposición fenomenológica: el análisis de un fenómeno significa auscultar la lógica que está a su base y lo traza. Por eso se puede decir que en el orden expositivo la comprensión aparece primero (Heidegger, 2015, p. 167), pero el fenómeno del tiempo es el suelo del que deriva la comprensión. Uno de los primeros elementos que reconoce Heidegger en su fenomenología es que el ser humano comprende: estamos en el mundo inmersos en espacios de significación, en horizontes de sentido. Este es también el primer paso de la fenomenología de Gadamer. Al continuar ahondando en el existir humano, Heidegger advierte que somos seres temporales, que nuestra existencia se juega en instantes en los cuales se cruza el pasado (o lo sido), la anticipación del futuro (o el advenir) y el presente. Nunca nos hallamos en la plena posesión del sentido, sino que la inmersión en él está fundada en una proveniencia del pasado, es decir, proyectamos nuestro existir desde un sentido que procede de antes.

Ahora, en el parágrafo 73 de Ser y tiempo, después de atacar una concepción vulgar o no pensada de la historia para la cual esta señala algo que ya sucedió y se canceló, Heidegger elabora el fenómeno de la historicidad. Se ve en la obligación de ir a este análisis, pues hasta ese punto de la obra pareciera como si la determinación de la temporalidad lanzara nuestra vista hacia adelante, es decir, resuelve el existir al advenir. La historicidad, en cambio, quiere mirar hacia atrás, hacia el pasado. ¿Cuál es la función del pasado en la caracterización temporal del Dasein? Lo primeramente histórico es el Dasein y no las cosas, pues estas últimas solo se insertan en los mundos de sentido que este abre; nosotros abrimos ciertas posibilidades, movemos el mundo y la historia. Este es el punto fundamental para entender en qué sentido somos historia. Pero no somos pasado en el sentido de algo que ya no somos; el pasado no es algo ya sucedido y cancelado, sino que por ejemplo el pasado que se presenta con un objeto antiguo señala posibilidades de significación que ya no están vigentes, y que tampoco están anuladas. Un 
museo o una antigüedad no es una entidad que no tenga nada que ver con nosotros, sino que muestran formas de vida y posibilidades de existencia que en algún sentido pueden actualizarse. El Dasein no puede entenderse como un pasado cancelado, sino que estamos lanzados a posibilidades que tuvieron un momento y que podemos reactualizar. Ello no quiere decir que repitamos las posibilidades, que ahora estemos por ejemplo incitados a tomar una ballesta, como en la edad media, para ir a cazar halcones o que, ante una afrenta, estemos llamados a lanzar un pañuelo al piso en señal de duelo. No se trata de revivir mundos de otras épocas. Lo propio del ser histórico del Dasein es que las posibilidades del pasado siguen siendo posibilidades, solo que en el mundo presente han perdido vigencia, y que pueden ser actualizadas desde otra situación de sentido. Así, el mundo medieval con sus caballeros, castillos, reinas y reyes, etc., no es algo que pueda ser entendido, como lo haría una concepción vulgar de la historia, como un pasado suprimido. Para una mirada no pensada de la historia el pasado ya se canceló, y lo que cuenta es el presente. Heidegger quiere mostrar que no somos pasado en ese sentido, sino en tanto se han cerrado ciertas posibilidades para abrir otras, pero las posibilidades que se han cerrado continúan ahí potencialmente. La forma de organización de las ciudades medievales, por ejemplo, puede tener aún algo por decir a los intentos modernos de planeación de la ciudad.

Cuando miramos Ser y tiempo en su conjunto reconocemos, como señala Gadamer, que el ser temporal del ser humano le da forma a la manera como comprendemos. Siempre abrimos sentido, pero esa apertura no es un dato absoluto, sino que viene de una tradición o, en términos de Heidegger, de una historicidad heredada, en la que de inmediato estamos y que permanentemente proyectamos. Por eso Gadamer entronca en Verdad y método la temporalidad del ser humano con su manera de comprender y de situarse en el mundo. Gadamer se apoya allí en Heidegger, pero quiere direccionar la problemática en una orientación distinta. El capítulo "La historicidad de la comprensión como principio hermenéutico" señala que, a pesar de los análisis de la historicidad en Ser y tiempo, Heidegger no tocó este problema porque su indagación tiene un interés más ontológico (Gadamer, 2007, p. 331). En el fondo, en Ser y tiempo el tiempo es el nombre para el ser, ser es tiempo. La temporalidad es allí una estructura ontológica superior, y por eso Heidegger deriva la historia de la temporalidad; su tema central sigue siendo el fenómeno del tiempo como horizonte último de la existencia, de manera que, al pasar en el parágrafo 76 por el fenómeno de la historicidad, lo hace solo de soslayo para después concentrarse nuevamente en la temporalidad. En ese sentido busca una ontología fundamental. A Gadamer, en cambio, le interesa la comprensión en su realización concreta 
en un mundo histórico, en el espacio social en el que se desenvuelven los individuos. Igual que en Heidegger, ese comprender vive en un sentido inmanente, pero le interesa mostrar que ese sentido se quiebra, nos obliga a reinterpretar y comprender, y en eso consiste el movimiento de la historia. Heidegger se enfoca en el replanteamiento de la pregunta por el sentido del ser, de modo que no llega a acentuar la historicidad de la comprensión, y por eso Gadamer surgiere que realmente es él quien detecta la historicidad de la comprensión. El proyecto de Gadamer es mostrar de entrada que toda comprensión es histórica: no podemos salir de nuestra tradición, leemos cualquier fenómeno desde nuestra situación de sentido.

En un punto central el proyecto de Gadamer se aleja del de Heidegger. Ser y tiempo está empeñado en hacer una fenomenología de la existencia desde el punto de vista del individuo, del Dasein enfrentado aisladamente con su propio mundo, con su comprensión determinada temporalmente por aquello previo que de inmediato abre su realidad. Se trata de analizar la existencia desde el individuo solitario (Gadamer, 2007, p. 332) ${ }^{3}$. Gadamer señala que, por el contrario, él no habla de la temporalidad vivida desde el Dasein, sino de la historicidad de la comprensión, que de inmediato tiene un nexo con la tradición, con un conjunto de referencias significativas que ya no son para un individuo sino para una comunidad. En consecuencia, lo que le importa a Gadamer del proyecto de Heidegger es elaborar desde allí un enfoque que le haga justicia a la dimensión histórica de la comprensión. Como su interés no es elaborar la comprensión a partir del individuo solitario, ni el comprender del Dasein sobre su propia existencia, sino determinar el comprender insertado en lo histórico en lo que estamos, situado en un mundo

\footnotetext{
${ }^{3}$ Esta crítica se le hace a menudo al Heidegger de Ser y tiempo: la dirección ontológica parece separar a la obra de problemáticas sociales e históricas concretas. No es claro incluso dónde queda el otro. Los primeros parágrafos de la obra analizan a un Dasein en soledad; el otro solo aparece más adelante, desde el parágrafo 26 sobre el ser-con. Por eso el existencialismo se sintió cómodo con este proyecto, pues se trataba del individuo confrontado con su existencia y con sus grandes dudas trascendentes, con el sentido último. No es fácil encontrarle a este planteamiento una coloración social, para la comunidad o para lo político. La filosofía de Gadamer, justamente por su carácter social, se liga más fácilmente con asuntos de filosofía social y política. Gadamer se apoya en Heidegger, pero hay un intento por lanzar la cuestión en otra dirección. La crítica de Gadamer a Heidegger no va en el sentido en que señaló Habermas: no se trata de hacer fecundo para las ciencias humanas la ontología fundamental de Heidegger (Habermas, 2000, p. 347), sino que su planteamiento tiene una dirección ontológica distinta. Además, en Heidegger se suma el problema difícil de su vinculación con el nacional-socialismo (Schürmann, 2013, p. 39). Para una mirada general de Ser y tiempo (Forero, 2019, pp. 275ss) y sobre el giro de Heidegger después de esta obra (Figal, 2016, p. 96). Una mirada amplia sobre el tiempo y la historia en Ser y tiempo la ofrece (Haar, 1994, p. 73).
} 
humano y social, él parte del punto de vista de la tradición. A Gadamer le interesa de inmediato la comprensión integrada al mundo social e histórico y por eso su análisis entronca de entrada con la hermenéutica espiritual científica, es decir, con Dilthey y el historicismo del siglo XIX.

Más allá de los diferentes caminos que toman las filosofias de Heidegger y Gadamer, importa acentuar que para ambos la historicidad implica una comunidad del ser humano con los otros y con el mundo en general, una pertenencia y familiaridad básica, primigenia. La crítica que se deriva de allí al mundo actual es justamente porque impulsa modos de conocimiento y de relación donde esas familiaridades se pierden; el mundo social, natural, nuestro propio mundo, el mundo de los otros, etc., se nos hacen extraños. Sus filosofías sociales, si se nos permite hablar así, tratan justamente de recordar ese tipo de comunidades y continuidades ante las amenazas del distanciamiento del sujeto con respecto a su mundo, del objetivismo del conocimiento, de la técnica y el capitalismo que cosifica las relaciones humanas, etc. Se trata de mantener o revivir esas continuidades de sentido.

Pues bien, ya Habermas reaccionó contra Heidegger y Gadamer, precisamente por este planteamiento (Habermas, 2007, p. 277). Según él, la historicidad es el hecho de que pertenecemos a tradiciones y que no podemos salir de ello. Heidegger y Gadamer nos dejan en una especie de claustrofobia, nos encerraran en la historicidad y en la tradición; sus filosofías no son suficientemente radicales, en tanto nos encierran en un mundo de sentido que llaman historicidad. En últimas, nos atan a la precomprensión y a la pertenencia a un suelo histórico (Habermas, 2007, p. 285). Más aún, la historia que nos es común, la historicidad, pasa por alto que en nuestras tradiciones también hay elementos de manipulación, que nuestra comunidad puede en realidad ser falsa o producto de, por ejemplo, el engaño y la propaganda. Nuestro mundo de sentido no es un elemento que nos aúna, sino el médium en el que habitan estructuras de poder y dominación. Se puede entonces crear una falsa comunidad en torno a un presunto pasado común, como lo hizo el nacionalsocialismo (Habermas, 2007, p. 300); por eso Habermas, y antes de él Adorno, denuncia en Heidegger y en Gadamer la ingenuidad de pensar en comunidades de sentido sin darse cuenta de las perturbaciones ideológicas que están allí presentes (Adorno, 1994, p. 74). Adorno y Habermas señalan irónicamente que a la ontología fundamental le faltan garras críticas, en tanto solo parece quedarse en comunidades inocentes. Se requiere más que esas filosofías pues las tradiciones pueden ser ideológicamente construidas, surgen de elementos de engaño y coacción, con la peculiaridad de que la gente crea que esa forma de vida es aceptable. 
En Gadamer hay una discusión con la tradición y con la autoridad que se deriva de ella (Gadamer, 2007, p. 344). El problema es que el fascismo, al que Heidegger adhirió y al que Gadamer se acomodó, hundió sus raíces en una defensa de la tradición del pueblo alemán. Para los críticos marxistas el papel de la tradición siempre sonó a un conservadurismo a ultranza; les parecía ver allí la frase que ya ironizaban Marx y Engels de las sociedades modernas: tradición, familia, propiedad y Estado. Con la confianza en la tradición y en la historicidad, Heidegger y Gadamer son incapaces de advertir sobre las perturbaciones y deformaciones que se introducen en ellas. Los individuos pueden vivir felices sin ver la ideología que se filtra en su situación de sentido. Detrás de todo puede estar el nacionalsocialismo, que apeló a la tradición y al que los alemanes suscribieron inocentemente. La fuerte experiencia del nacionalsocialismo revela el apoyo de una tradición por todo un pueblo, sin que se viera lo perverso que habitaba en ese proyecto (Habermas, 1989, p. 254). Aún más, la crítica de Habermas y Adorno es que las filosofías de Heidegger y Gadamer no representan un proyecto emancipador o transformador de las sociedades. Se trata de filosofías empeñadas en elucidar y determinar con mucha precisión estructuras generales y amplias del existir humano, pero que dejan intactos aspectos esenciales del mundo social. A la hermenéutica le falta un arsenal conceptual emancipador que permita bascular ciertas estructuras injustas de la sociedad.

La salida de Habermas a este problema consiste en que al planteamiento de la hermenéutica le falta reflexión, esto es, ilustración, pues solo así podemos cortar el cordón con nuestro pasado o, por lo menos, reconocer que las tradiciones pueden portar una carga perversa que la gente corriente es incapaz de advertir. Las patologías de las sociedades no se ven a sí mismas espontáneamente, sino que requieren de críticos de las ideologías, de filósofos emancipadores, de una vanguardia social que detecte aquello que para el ciudadano corriente pasa como subrepticiamente (Habermas, 2007, p. 304); claramente las filosofías de Heidegger y Gadamer son incapaces de detectar esos elementos por su confianza en la reelaboración silvestre de las tradiciones. Habermas señala entonces que el uso de la razón (comunicativa) debería permitir que nos separemos progresivamente de nuestro entorno. Este marco del habla racional señala el desarrollo normal de la comunicación, y con él se puede denunciar, en el seno de lo social, lo anormal, desviado o patológico. En otras palabras, como las grietas o ideologías solo pueden ser determinadas mediante una teoría de la razón que pueda confrontarse con el acontecer del mundo real, el proyecto habermasiano de una filosofía crítica se propuso crear un modelo del habla racional que atravesaba a las culturas y a las tradiciones. Se trataba de elaborar una teoría de la praxis no alienada, 
no contaminada por distorsiones, ideologías, dominación o poder (Forero, 2013, p. 63). Para una parte de la teoría crítica esta empresa sí tiene dientes subversivos, pues desde allí es posible volver a las culturas y tradiciones para evaluarlas críticamente. La idea de Habermas, y del Honneth de los años noventa, es que la comprensión necesita una teoría que nos permita identificar los malentendidos y distorsiones ideológicas; pues para denunciar el sinsentido no podemos entregarnos, como lo hacen Heidegger y Gadamer, a una especie de confianza en las tradiciones. ¿Cómo puede reaccionar la filosofía hermenéutica ante estas observaciones?

\section{Tiempo e historicidad. Esbozo de una filosofía crítica de la sociedad}

Habermas y Honneth han tratado de mostrar que el distanciamiento con respecto a la realidad tiene un lado productivo y ofrece una posibilidad crítica. Heidegger y Gadamer, por su parte, rechazan todo tipo de extrañamiento pues consideran que con él perdemos la familiaridad, implicación y pertenencia al mundo en el que nos hallamos (Gadamer, 1998, pp. 232-233). Toda objetivación expresa la alienación del mundo contemporáneo. Pero se plantea la pregunta de si hay otra manera de elaborar una filosofía crítica que no sea desde la distancia. Sostengo que el tiempo es un concepto crítico, cuando se lo articula desde todas sus dimensiones.

Fue Heidegger quien señaló que el ser humano es un ser-en-el-mundo en el sentido de que ya está vinculado con un espacio de significatividad. Su idea central es que hay una experiencia originaria de pertenencia a un entorno de significaciones que nos es familiar. Gadamer se apropia de esta posición central. En Verdad y método los prejuicios corresponden básicamente a nuestra situación histórica; los tenemos porque participamos de un mundo socio-histórico que de antemano orienta la praxis, el conocimiento, la situación en el mundo, etc. El comprender muestra los prejuicios que tenemos por el hecho de haber nacido en una situación de sentido que nos dota de una perspectiva; este es el nivel al que aún juega Habermas en su crítica a Gadamer, pues liga prejuicio a una situación cultural, en la cual hay un lenguaje natural que se impone y lleva consigo unas cargas de significación que nos terminan orientando. A Gadamer le interesa acentuar los prejuicios para las ciencias históricas: un historiador desde que escoge su tema ya está prejuiciado, habita en una tradición de investigación que le señala lo que es cuestionable o no (Gadamer, 1998, p. 233).

Pues bien, en un pasaje decisivo de Verdad y método Gadamer se pregunta cómo es posible distinguir los prejuicios falsos de los correctos; la respuesta, dice él, está en la distancia en el tiempo (Gadamer, 2007, p. 360). A él no le interesa tanto el asunto metodológico de cómo diferenciar los 
prejuicios verdaderos de los falsos, como el asunto ontológico fundamental de cómo sacar en claro que los prejuicios se van abriendo a unos nuevos, es decir, mostrar que el tiempo no es una coordenada vacía y neutral que va sucediendo, sino que va produciendo sentido o, en otra formulación, que tiempo es la producción misma de sentido. Allí se habla del acontecer del tiempo: "la distancia en el tiempo debe ser reconocida como una posibilidad positiva y productiva del comprender. No es un abismo devorador, sino que está colmada por la continuidad de la procedencia y de la tradición, a cuya luz se nos señala todo lo transmitido. No será aquí demasiado hablar de una genuina productividad del acontecer (einer echten Produktivität des Geschehens)" (Gadamer, 2007, p. 367). Gadamer señala la productividad que brota del hecho de que los horizontes de sentido están en una transformación y movilidad permanente; unas líneas arriba, había dicho que la distancia en el tiempo solo puede ser pensada desde el giro ontológico que practicó Heidegger; este había dicho que "la apertura del acontecer histórico llevada a cabo por la historiografía está enraizada, en sí misma y en su propia estructura ontológica ... en la historicidad del Dasein" (Heidegger, 2015, p. 405). Podemos explicar este argumento con recurso a lo que Heidegger denomina una comprensión vulgar del tiempo. No hay historia humana por el hecho de que caminemos sobre una línea de tiempo y una sucesión infinita de ahoras, sino que existen los años y la sucesión de épocas porque en esencia somos históricos, producimos historia, cambiamos sentidos y de allí extraemos la temporalidad, que después podemos graficar con líneas abstractas y medirla, como en el caso de la física de Newton donde el tiempo se vuelve una coordenada universal vacía; pero esa representación es secundaria. El tiempo subsidiario o abstracto es el que se puede contar; el historicismo cae preso de ese tiempo vacío y por eso, en su extremo, asume que en cada ahora, cada época, cada cultura, debe tener un horizonte de sentido diferente y cerrado. El historicismo considera que el tiempo es una línea sobre la cual se trazan horizontes particulares de sentido.

El escrito de 1874 de Nietzsche titulado "De la utilidad y los inconvenientes de la historia para la vida" empieza preguntando por el modo como vivenciamos el tiempo o, si se nos permite, interroga su realidad fenomenológica (Nietzsche $K S A, 250$ ). Nietzsche no elabora un modelo teórico sobre el fenómeno del tiempo, como el que propuso el historicismo que lo encuentra como una sucesión de ahoras vacíos, cerrados, inconmensurables e indiferentes entre sí, sino que habla del modo como en la experiencia inmediata vivenciamos el tiempo. ¿De qué manera el tiempo nos choca en nuestra experiencia? Nietzsche asegura que vivenciamos el tiempo a la manera de un recordar que cae. Se trata de una experiencia del 
tiempo más inmediata, en la que el pasado deja de ser un punto neutro atrás, y se convierte en un recuerdo que llegó, y el futuro es la proyección de lo que vamos a hacer. Esta es una experiencia real e histórica del pasado, del presente y del futuro, no ahoras vacíos, sino que cada dimensión está llena de sentido. El tiempo es entonces la deriva del sentido. Ese es el punto de Heidegger y Gadamer: el tiempo solo existe porque el sentido va cambiando. Lo primario es la existencia y las tradiciones que van transformando nuestra visión de mundo. El tiempo no es una dimensión en sí, como en Newton, no se puede objetivar o representar como una línea sobre la cual caminan las comunidades y los individuos, sino que surge en el cambio y movilidad de los horizontes de sentido, es lo que se produce por el desplazamiento de las tradiciones. Dicho de otra manera, la existencia es temporal en tanto ella temporiza, genera tiempo. Y es la deriva del sentido la que da la impresión de que hay una línea vacía de tiempo.

El historicismo asumió que había una línea de tiempo vacía que luego se llenaba con horizontes de sentido incomunicados, mientras que Gadamer muestra que la temporalidad es acontecer de sentido. Esto es lo más humano y real: hay horizontes transformándose unos en otros y esa continuidad de los horizontes da la impresión de la sucesión temporal. Nuestras tradiciones se están reconstituyendo y desplazando constantemente y es eso lo que hace representar el tiempo como una línea en la que suceden eventos. Tiempo no es sino el acontecer constante de sentido que viaja en las distintas comprensiones de las épocas. Se deforma entonces el asunto de la distancia en el tiempo en Gadamer cuando se piensa que conduce a esperar, por ejemplo, una década mientras se decantan los prejuicios y vemos si lo que hoy pensamos es falso o correcto. A él le interesa destacar el carácter productivo del acontecer que hace que cada vez que comprendemos lo hagamos de manera distinta, porque estamos situados en un horizonte que se ha desplazado.

Gadamer avanza más allá de donde él mismo se da cuenta. En la discusión con los prejuicios le interesa la productividad del acontecer que va generando nuevos sentidos útiles para abrir nuevas significaciones en las cosas. En consecuencia, la idea de distinguir los prejuicios no es la de diferenciar lo correcto frente a lo unilateral, sino que el prejuicio correcto es aquel que es capaz de potenciar el acontecer de sentido, de abrirlo en otras direcciones. La tarea no es pues distinguir los prejuicios verdaderos de los falsos, sino poner en juego nuevas orientaciones de sentido que permitan ver las nuevas facetas de la tradición que no se veían. Interesa la productividad del tiempo y de la tradición, el hecho de que se generen nuevos prejuicios, porque tiempo y tradición son acontecer de sentido. En consecuencia, 
pertenecer a la tradición implica estar en una movilidad de sentido siendo afectado por cosas que vienen de atrás y abiertos a un potencial permanente de alteridad.

En este planteamiento resuena, desde luego, Heidegger. En el parágrafo 74 de Ser y tiempo se quiere entender lo que significa hacer historia. Heidegger determina el carácter histórico del Dasein preguntando cómo ocurre la resolución, es decir, cómo asumimos o nos resolvemos a empuñar nuestra existencia. La pregunta es de dónde salen esas posibilidades: ¿se encuentran en el Dasein o este se las inventa? La idea es que las posibilidades que realizan la existencia nunca son traídas de los cabellos o inventadas por nosotros, sino que se encuentran en nuestra facticidad, en el mundo que es lo mismo que en el parágrafo 75 Heidegger llama tradición. El acontecer histórico no consiste en un caótico suceder de acontecimientos, sino en un movimiento por el cual las posibilidades heredadas e inscritas en la tradición son asumidas, y reintroducidas y modificadas en circunstancias nuevas. Esa imbricación entre pasado, presente y futuro es lo que le da sentido y continuidad a la historia. En otra formulación, para Heidegger la existencia propia decide su curso de acción a través de una mirada a las posibilidades heredades de la tradición que le abren vías de acción hacia adelante. Pues bien, si esto es así, entonces la cuestión que ahora se plantea para una filosofía crítica es la de cómo movilizar nuevas orientaciones de sentido que abran nuestras tradiciones en otras direcciones, es decir, debemos distinguir entre los prejuicios o tradiciones que frenan u obstaculizan el acontecer de la tradición, frente a las visiones de mundo que son orientaciones de sentido que permiten la apertura.

En este mismo punto la filosofía de Heidegger puede hacer una aportación. Para él, el prejuicio del ser como presencia determina toda una época; se trata de un prejuicio paralizador, y justamente allí resulta interesante volver a su filosofía para hacerla crítica, pero no en el sentido de una crítica singular a una situación, sino crítica de la historia de la metafísica como olvido del ser, que es otra forma de decir como olvido de la temporalidad en todas sus dimensiones.

\section{Heidegger y el prejuicio que envara el acontecer: la presencia}

El mismo Gadamer se remite a Heidegger señalando que es posible pensar en el concepto de prejuicio en un sentido más ontológico que histórico, es decir, no desde los prejuicios que portamos como seres situados epocalmente, sino desde la historia del sentido del ser. Gadamer escribe: "En Ser y tiempo [Heidegger] concreta la proposición universal, que él convierte en problema hermenéutico, transportándola al problema del ser. Con el fin de 
explicar la situación hermenéutica del problema del ser según el tener previo [Vorhabe], el ver previo [Vorsicht] y el concebir previo [Vorgriff], examina la cuestión que él plantea a la metafísica confrontándola críticamente con hitos esenciales de la historia de la metafísica" (Gadamer, 2007, p. 336). ¿Qué relación guarda el concepto de prejuicio con la historia del ser? A todos nos corresponden prejuicios por nuestro carácter social e histórico, pero más profundamente hay un prejuicio que tiene que ver con nuestro carácter temporal. Este es el tránsito de la historicidad a la temporalidad. Con la historicidad reconocemos que hacemos parte de un todo socio-histórico, mientras que la temporalidad implica una cierta preminencia del presente, de lo que se impone y esa es la fuente de todos los prejuicios a los que después se les pone nombres y contenidos concretos. La referencia aquí es la discusión de Heidegger con la historia de la metafísica, pues las épocas metafísicas son el intento de olvidar u ocultar el acontecer de sentido y dejarlo quieto como en una imagen. Según él, podemos leer la historia de la metafísica como el intento por captar el ser únicamente desde el aspecto de la presencia, lo siempre presente. El ser para la metafísica es lo permanentemente estático o la presencia, pero esta es solo una de las dimensiones del tiempo; lo que entiende la metafísica por ser surge pues de una comprensión del fenómeno del tiempo que es recortado allí a lo absolutamente presente. El proyecto de Ser y tiempo en su conjunto se proponía mostrar el tiempo como horizonte de toda comprensión del ser, pero no el tiempo reducido de la metafísica. Al ganar una comprensión del tiempo que no se limita al presente, cambia nuestra comprensión del ser. En Ser y tiempo leemos: "Desde un punto de vista existencial formal, y sin mencionar constantemente todo su contenido estructural, la resolución precursora es un estar vuelto hacia el más propio y eminente poder-ser. Esto último sólo es posible en tanto que el Da-sein puede, en general, venir hacia sí mismo en su posibilidad más propia y en tanto que en este dejar-se-venir-hacia-sí-mismo soporta esa posibilidad en cuanto posibilidad, es decir, existe. El dejar-se-venir hacia sí mismo soportando la posibilidad eminente, es el fenómeno originario del porvenir [Zukunft]" (Heidegger, 2015, p. 340). El asunto es que, al ampliar nuestra concepción del tiempo, cambia necesariamente la concepción que tenemos de ser más allá de la pura presencia.

En últimas, olvido del ser o del tiempo es olvido de que la realidad está aconteciendo y pasa a imponerse una visión de mundo como hecho dado y estático. Lo que de aquí le interesa a Gadamer es que esa es la fuente última del prejuicio. Para Heidegger, la historia de la metafísica es la de la cultura occidental hasta el momento, en la que se olvidó el carácter fundamentalmente aconteciente de la realidad, que el mundo está surgiendo 
a cada instante y, en ese sentido, cambia permanentemente. Del olvido resulta que las constelaciones objetivas se impongan con una fuerza tal que perdemos de vista su carácter de ser aconteciente, de modo que nos satisfacemos con la pura presencia de positividades. Heidegger formula esto diciendo que la metafísica olvida el carácter temporal del ser humano que siempre es retrospectivo, prospectivo y fáctico, y se fija en una sola dimensión del tiempo que es el presente (Heidegger, 2015, p. 343); este prejuicio se nos escapa permanentemente, terminamos pensando que la realidad está constituida de constelaciones fácticas o, en otras palabras, que el mundo es de manera definitiva. Después llegan las constelaciones culturales a darle color a esto, y a significarlo de manera concreta; pero previamente está ese prejuicio más ontológico.

La apelación de Gadamer a Heidegger muestra entonces que él no está pensando al nivel historicista o de la tradición, sino a un nivel filosófico porque reconoce que a la base de todos los prejuicios con los cuales nos orientamos está un meta-prejuicio. Se trata del prejuicio por el cual constituimos un mundo de hechos presentes. Es este prejuicio el que nos hace olvidar el carácter temporal y deviniente de las cosas y nos planta ante una realidad como constituida de hechos fijos y fácticos. Gadamer no solo señala entonces que toda época histórica porta consigo una multiplicidad de prejuicios que terminan orientado a los individuos, sino que pone en evidencia una estructura de ser según la cual hace parte de la experiencia que el mundo que termina edificándose e imponiéndose es el de un sentido presente y olvidamos el acontecer fundamental que está a la base. El primer prejuicio es el de estabilizar el mundo, y luego lo aquietamos a partir de ciertos contenidos, que ya señalan los prejuicios culturales concretos, situados e históricos como las sociedades de clases, racistas, patriarcales, coloniales, etc. En este punto no se habla de prejuicios históricos concretos que la filosofía crítica debiera denunciar, sino de los prejuicios que resultan del problema del ser y de la historia de la metafísica ${ }^{4}$.

Desde esta perspectiva se abre un sentido crítico para el saber histórico: quien hace historia no afronta el pasado con el interés de domesticarlo o darle continuidad, sino de destacar su potencial de alteridad y poder de

\footnotetext{
${ }^{4}$ Desde esta elaboración del tiempo podemos conectar con planteamientos recientes de la teoría crítica. Hartmut Rosa, por ejemplo, ha insistido en el tiempo como un elemento fundamental dentro de la alienación. Su tesis frente a Marx es que, en una dimensión más profunda que la explotación en torno al trabajo, están las distorsiones en nuestra experiencia del tiempo; de allí derivan formas de alienación menos visibles, pero más fundamentales. (Rosa, 2009, p. 77). Ya Gabriel García-Márquez ofrecía elementos para pensar esa teoría crítica del tiempo (García-Márquez, 2007, p. 56). Sobre el fenómeno del tiempo para una filosofía social crítica y para una sociología crítica (Dörre, Lessenich y Rosa, 2009).
} 
confrontación. La historia rompe la realidad fáctica y la abre en diferentes posibilidades. Otras ciencias sociales se pueden proponer encontrar continuidades en su tiempo y asegurar ciertos ejes de una tradición. Se trata en algún sentido de achatar y aplanar las alteridades, incluirlas dentro de algo que pueda ser manejable y comprensible; pero la experiencia de la historia no puede tener esa pretensión, pues por su objeto mismo rompe la continuidad del sentido. La historia escandaliza, es decir, su vocación no es tanto ver una continuidad de instituciones, culturas, formas de organización, etc., como mostrar que la realidad podría ser completamente opuesta, que lo que vemos puede ser absolutamente ficticio, y que dentro de nuestro mundo de sentido puede haber otras líneas de desarrollo. Dicho de otra forma, el saber histórico, frente a toda ciencia social normalizada y disciplinada, está más cerca del carácter deviniente y cambiante de la realidad.

Podemos expresar esta tesis con el vocabulario de Gadamer. En la segunda parte de Verdad y método se señalan varios registros del intérprete, dos de los cuales resultan importantes para nosotros. En principio todos somos espontáneamente intérpretes, pero hay un nivel interpretativo más especializado que sería el del historiador. Lo que allí se denomina fusión de horizontes es una tarea explícita para los científicos sociales y para la historia en particular. Con nuestro pasado no hay horizontes separados ni aislados, sino que, más bien, siempre tenemos una continuidad con la tradición. Sin embargo, es tarea del saber histórico destacar una especie de horizonte ajeno que le permita ver la alteridad y reconocer lo extraño del pasado. El trabajo histórico no se queda en el elogio a la familiaridad y a la continuidad del sentido, sino que moviliza el sentido al reconocer lo ajeno de un fenómeno. En el fondo, la historia pone en acción ese saber espontáneo, esa precomprensión en la que todos vivimos, en tanto moviliza la realidad en sentidos múltiples y distintos. Se trata de un saber que no se deja imponer la familiaridad y por eso debe ser receptivo para la diferencia o alteridad. La tarea explícita de la historia es la sensibilidad para las grietas que se producen en el sentido, para lo otro que significa una comunidad de significación en un momento dado. La fusión de horizontes que practica la historia significa que el intérprete separa el horizonte ajeno, destaca el horizonte de lo otro y con ello rompe la familiaridad para que podamos ver lo propio, comprendernos a nosotros mismos y reconocer las limitaciones de nuestro espacio de sentido. Este saber introduce un elemento crítico, pues, lejos de todo romanticismo que afianza la continuidad de la tradición, constituye una búsqueda sistemática de la alteridad. 


\section{Referencias bibliográficas}

Adorno, T. W. (1994). Actualidad en la filosofía. Barcelona, España: Altaya.

De Lara, F. (2014). Interpretación, historicidad y negación. Sobre el lugar político de la filosofía en Heidegger y Adorno. Revista Internacional de Fenomenología y Hermenéutica Alea, (12). 11-26.

De Lara, F. (2019). Presentación. El diálogo con Heidegger en el primer proyecto filosófico de Marcuse. Enrahonar. An International Journal of Theoretical and Practical Reason, 62, 5-18. doi: 10.5565/rev/enrahonar.1243.

Dörre, K., Lessenich, S., Rosa, H. (2009). Soziologie, Kapitalismus, Kritik. Eine Debatte. Fráncfort del Meno, Alemania: Suhrkamp.

Figal, G. (2016). Martin Heidegger. Zur Einführung. Hamburgo, Alemania: Junuis Verlag.

Forero, F. (2013). El Hegel de Habermas: la Teoría de la acción comunicativa como precisión y desarrollo del programa esbozado en la filosofía hegeliana del periodo de Jena. Revista colombiana de sociología, 36(2), 49-80. doi: 10.15446/rcs.

Forero, F. (2018). Democracia, lógica y política. Sobre Hegel, Marx y Abensour. En L. E. Gama, D. Paredes y A. Parra (Comps.), Diálogos con Marx (pp. 229-255). Bogotá, Colombia: Editorial Universidad Nacional de Colombia.

Forero, F. (2019). Filosofía y negatividad. Sobre el camino del pensar de Hegel en Jena. Bogotá, Colombia: Editorial Universidad Nacional de Colombia.

Gadamer, H.-G. (1998). Verdad y método II. Salamanca, España: Sígueme.

Gadamer, H.-G. (2000). Freundschaft und Solidarität. En Ed. J. Rothfuss y H.-E. Koch (Eds.), Konstanten für Wirtschaft und Gesellschaft, Festschrift für Walter Witzenmann (pp. 178-90). Constanza, Alemania: Konstanz Labhard Verlag.

Gadamer, H.-G. (2007). Verdad y método. Salamanca, España: Sígueme.

Gama, L. E. (2018). Marx y Hegel: de la inversión al diálogo. En L. E. Gama, D. Paredes y A. Parra (Comps.), Diálogos con Marx (pp. 29-54). Bogotá, Colombia: Editorial Universidad Nacional de Colombia.

García-Márquez, G. (2007). Cien años de soledad. Madrid, España: Real Academia Española.

Habermas, J. (1989). El discurso filosófico de la modernidad. Buenos Aires, Argentina: Taurus.

Habermas, J. (2000). Perfiles filosófico-políticos. Madrid, España: Taurus.

Habermas, J. (2007). La lógica de las ciencias sociales. Madrid, España: Tecnos.

Haar, M. (1994). La fracture de l'Histoire. Douze essais sur Heidegger. París, Francia: Jérôme Millon.

Heidegger, M. (2015). Ser y tiempo. Madrid, España: Trotta.

Honneth, A. (1998). La lucha por el reconocimiento. Por una gramática moral de los conflictos sociales. Barcelona, España: Crítica.

Honneth, A. (2007). Reificación. Un estudio en la teoría del reconocimiento. Buenos Aires, Argentina: Katz.

Jaeggi, R. (2014). Alienation. Nueva York, EUA: Columbia University Press.

Marcuse, H. (1928). Beiträge zu einer Phänomenologie des historischen Materialismus. Philosophische Hefte, 1(1), 45-68. 
Marx, K. (2013). Manuscritos de economía y filosofía. Barcelona, España: Yulca. Nietzsche, F. (KSA) (1999). Kritische Studienausgabe. Vol I. Berlín, Alemania: Walter de Gruyter.

Ricoeur, P. (1986). Du texte à l'action. Essais d'herméneutique II. París, Francia: Éditions du Seuil.

Rosa, H. (2009). Social Acceleration: Ethical and Political Consequences of a Desynchronized High-Speed Society. En: H. Rosa and W. Scheuerman (Eds.), High-speed society: social acceleration, power, and modernity (pp. 35-67). Pensilvania, EUA: The Pennsylvania State University.

Rosa, H. (2016). Alienación y aceleración. Hacia una teoría crítica de la temporalidad en la modernidad tardía. Buenos Aires, Argentina: Katz.

Rosenkranz, K. (1844). Georg Wilhelm Friedrich Hegel's Leben. Supplement zu Hegel's Werken. Berlín, Alemania: Verlag von Duncker und Humblot.

Schürmann, R. (2013). Le principe d'anarchie. Heidegger et la question de l'agir. París, Francia: Diaphanes.

Taylor, C. (2009). La política del reconocimiento. En C. Taylor (Ed.), El multiculturalismo y "la política del reconocimiento" (pp. 53-116). Ciudad de México, México: Fondo de Cultura Económica.

Taylor, C. (2005). La libertad de los modernos. Buenos Aires, Argentina: Amarrortu. 